\title{
POLÍTICAS PÚBLICAS EM EDUCAÇÃO: A AVALIAÇÃO COMO UM PROBLEMA CURRICULAR CONTEMPORÂNEO
}

\author{
André Vitor Fernandes dos Santos ${ }^{1}$ \\ Letícia Terreri Serra Lima²
}

\begin{abstract}
Resumo
O presente trabalho tem por objetivo apresentar uma reflexão acerca das políticas de avaliação que vigoram, atualmente, no cenário educacional brasileiro, problematizando a usual articulação entre elas e a garantia da qualidade da educação. Para isso, dialogamos tanto com autores que vêm debatendo as políticas de avaliação no âmbito das políticas públicas em Educação, em análises macrossociais (LEHER, 2007; OLIVEIRA et al., 2011; OLIVEIRA; FELDFEBER, 2011; entre outros), quanto com autores que debatem tais políticas no âmbito das políticas de currículo, com especial atenção àqueles que operam com a noção de Ciclo de Políticas de Stephen Ball (LOPES, 2005; MAINARDES, 2006; TERRERI, 2008; DIAS, 2009; SANTOS, 2010). Entendendo que ambos os campos de discussão são potentes e oferecem múltiplas possibilidades de análise, apontamos o que nos parecem aspectos férteis tanto para compreender o cenário educacional contemporâneo quanto para lutar em defesa da autonomia da Escola Pública e da ação docente.
\end{abstract}

Palavras-chave: Avaliação Educacional; Políticas Públicas em Educação; Ciclo Contínuo de Políticas.

\begin{abstract}
This paper aims to present a reflection about the current educational evaluation policies in Brazilian educational scenario, questioning the usual linkage between them and the guarantees for the quality of education. As an strategy for that we dialogue with authors who discuss the educational evaluation policies in the context of the public ones in education, in macro-analysis (LEHER, 2007, OLIVEIRA et al., 2011; FELDFEBER; OLIVEIRA, 2011 and others), and with authors who are debating such policies within the curriculum policy, with special attention to those operating with the Stephen Ball's notion of the Continuous Cycle Policy (LOPES, 2005; MAINARDES, 2006; TERRERI, 2008; DIAS, 2009; SANTOS, 2010). Taking into account that both fields of discussion are influential and offer multiple possibilities of analysis, we point out the aspects that seem to be useful both to comprehend the contemporary educational scene as to go for the autonomy of the Public School and teaching action.
\end{abstract}

Keywords: Educational Evaluation; Public Policy in Education; Continuous Policy Cycle.

\footnotetext{
${ }^{1}$ UFRJ. andrevfsantos@gmail.com

${ }^{2}$ UFRJ. leterreri@gmail.com
} 


\section{INTRODUÇÃO}

Este trabalho tem por objetivo apresentar uma reflexão acerca das políticas de avaliação que vigoram, atualmente, no cenário educacional brasileiro, problematizando a usual articulação entre elas e a garantia da qualidade da educação.

A preocupação com a garantia da qualidade da educação não é recente no pensamento pedagógico brasileiro. Na década de 1920, por exemplo, têm-se o registro da luta de educadores em torno da qualidade, o que se materializa na fundação da Associação Brasileira de Educação (ABE). Mais tarde, em 1932, essa luta assume novos contornos com o lançamento do Manifesto dos Pioneiros da Educação Nova em meio ao processo de reordenação política que vivia o Brasil daquela época (SAVIANI, 2009). Tendo como principais representantes educadores como Anísio Teixeira, Fernando de Azevedo e Lourenço Filho, esse movimento, ainda que dentro de uma matriz de pensamento liberal, defendeu a democratização das oportunidades educacionais e a garantia de uma educação de qualidade a todos os cidadãos, compatível com o desenvolvimento econômico do país.

Na virada dos anos de 1950 para a década de 1960 tivemos a Campanha em Defesa da Escola Pública, em grande parte impulsionada pela tramitação final da Lei de Diretrizes e Bases $(L D B)^{3}$. Mais recentemente, no contexto da redemocratização do país ocorrem as Conferências Brasileiras de Educação e o Fórum Nacional em Defesa da Escola Pública, que vieram a ter influências tanto na Constituinte como na nova LDB (SAVIANI, 2009). Todos esses episódios têm em comum o fato de aglutinarem um contingente considerável de educadores em torno de 'bandeiras' como a universalização do acesso à educação básica, a igualdade de oportunidades para estudantes oriundos de todas as classes sociais e a qualidade da educação.

A partir da década de 1980, as discussões sobre a qualidade da educação transbordam para além do círculo dos profissionais da educação, proporcionando uma maior participação social. Essa nova configuração tem suscitado uma série de ações que visam ampliar o controle social por meio da publicização de índices, como o Ideb (Índice de Desenvolvimento da Educação Básica), alcançados por escolas, municípios e estados. Como nos relata Saviani $(2009$, p.31),

o que confere caráter diferenciado ao Ideb é a tentativa de agir sobre o problema da qualidade do ensino ministrado nas escolas de educação básica, buscando resolvê-lo. E isso veio ao encontro

\footnotetext{
${ }^{3}$ Referimo-nos à Lei no 4.024, de 20 de dezembro de 1961.
} 
dos clamores da sociedade diante do fraco desempenho das escolas à luz dos indicadores nacionais e internacionais dos alunos. Esses clamores adquiriram maior visibilidade com as manifestações daquela parcela social com mais presença na mídia, em virtude de suas ligações com a área empresarial. Tal parcela só mais recentemente vem assumindo a bandeira da educação, em contraste com os educadores, que apresentam uma história de lutas bem mais longa.

A criação de um parâmetro para comparação de resultados entre diferentes instituições e ao longo do tempo atende aos clamores da sociedade, trazendo, também, à discussão representantes do setor empresarial, que só mais recentemente passaram a focalizar a educação e a (con)formar as instituições educacionais de modo a atender a alguns de seus interesses (SAVIANI, 2009). À guisa de problematizar essa suposição, passamos nas seções seguintes a uma reflexão que envolve, em um primeiro momento, situar historicamente a centralidade que a avalição em larga escala tem assumido nas políticas públicas em Educação. Em diálogo com documentos oficiais e com trabalhos do campo de Políticas Públicas, interpretamos percursos descritos por algumas avaliações externas dirigidas à educação básica e a sua relação com a garantia da qualidade da educação.

Finalmente, à luz dos referenciais do campo do Currículo, apontamos como essas políticas, ainda que com um viés de controle do trabalho docente e centradas na obtenção de resultados previamente projetados, vêm contribuindo para ressignificar o currículo nas instituições escolares. Problematizamos não só seu caráter constrangedor e impositivo, mas, sobretudo a dimensão produtiva que permeia as relações de poder que constituem os fenômenos sociais, dentre eles, o processo de produção das políticas educacionais.

\section{A CENTRALIDADE DA AVALIAÇÃO NAS POLÍTICAS PÚBLICAS EM EDUCAÇÃO}

Antes de entrar no debate acerca das políticas de avaliação que figuram hoje no cenário educacional brasileiro, nos parece inevitável voltar algumas décadas para compreender o contexto histórico mais amplo que contribuiu para sua consolidação enquanto instrumento de mensuração da qualidade da educação. Assim, nesta seção, dialogamos com algumas produções acadêmicas que têm se debruçado sobre o tema, reconhecendo os limites espaço-temporais de nosso trabalho que não têm o contexto histórico como foco central. 
Baseando-nos em Leher (2007), remontamos à década de 1980 para compreender a Crise da Dívida, de 1982, como um marcador temporal imprescindível de ser levado em consideração no entendimento das políticas sociais que vêm se desenvolvendo nos países da América Latina desde então. Impossibilitados de receber "auxílio financeiro" dos órgãos internacionais (Fundo Monetário Internacional - FMI e Banco Mundial - BM), muitos destes países caminharam no sentido de negociar a dívida sob a condição de reformas estruturais conduzidas, principalmente, pelas frações das classes dominantes locais (LEHER, 2007).

No que concerne às políticas sociais, esta negociação imprimiu transformações em todas as esferas e dimensões, se distanciando de anseios universalistas pela educação, ciência e tecnologia. Segundo Leher (2007), grande parte dos países da América Latina fez reformas constitucionais modificando o direito à educação, que passou a ser concebida como um serviço a ser negociado no mercado. Especialmente no Brasil,

a concepção de que a educação é um serviço está expressa no Plano Diretor da Reforma do Estado, iniciado no governo Cardoso (1996) e aprofundado na lei de parcerias público-privadas (governo Lula da Silva), que preconiza a maior eficácia do setor privado frente ao público no atendimento educacional dos segmentos populares (LEHER, 2007, p.10).

Em relação às políticas educacionais, mais especificamente, Oliveira et al. (2011) destacam as medidas de descentralização da educação, que têm como importante marco a Constituição Federal de 1988, quando os Municípios passam a entes da Federação, com autonomia política. A descentralização administrativa, financeira e pedagógica, tanto dos recursos quanto das responsabilidades, pode ser interpretada como um dos grandes eixos da reforma que se realizou na educação brasileira, resultando em transferência de responsabilidade dos órgãos centrais para os locais, em novos modelos de gestão do ensino público, mais flexíveis que, ao mesmo tempo em que atribuíram maior autonomia à unidade escolar, passaram a exigir da escola novos papéis (OLIVEIRA et al., 2011).

Neste cenário, a justificativa para o processo de descentralização estava relacionada à democratização e a uma maior racionalização da gestão da educação. A partir da repartição de responsabilidades do Estado no cumprimento de um dever legal para com a população, "o regime de colaboração entre as diferentes esferas administrativas foi considerado um meio indispensável à constituição de fato de um sistema que possibilitasse a focalização do atendimento aos mais necessitados, funcionando de maneira integral e articulada" (OLIVEIRA 
et al., 2011, p.17).

Em diálogo com Oliveira e Feldfeber (2011), é importante atentar para a grande relevância dada à gestão, somada ao enxugamento do Estado, nas reformas neoliberais que tiveram lugar nos anos de 1990, em países da América Latina. As autoras chamam a atenção para o fato de que essa cultura da gestão que, no caso mais específico da educação, retoricamente deveria conferir maior autonomia às escolas, assume traços característicos de modelos de gestão empresarial capitalista em que a participação dos atores sociais se converte em fator-chave do êxito ou do fracasso das ações implementadas.

Na mesma direção, Pini e Melo (2011, p.41) indicam que as políticas educacionais na América Latina, sob enfoques neoliberais e neoconservadores, adquirem traços das recomendações das agências multilaterais, priorizando "a eficiência e a qualidade, a avaliação compreendida como padrões ou indicadores, a descentralização e a autonomia, a privatização e a orientação para uma formação de recursos humanos, a fim de aumentar a competitividade internacional das economias nacionais".

No esteio de uma nova regulação social e educativa, diversas medidas surgem como "soluções técnicas e políticas para a resolução de problemas de ineficiência administrativa dos sistemas escolares ou da busca de adequação e racionalização dos recursos existentes" (OLIVEIRA et al., 2011, p.12). Ao mesmo tempo em que é defendida a maior participação local e a autonomia das escolas, é fortalecida a ideia da necessidade de transparência, prestação de contas e demonstração de resultados, retirando cada vez mais do Estado seu papel executor e transferindo para a sociedade a responsabilidade pela gestão dos serviços, alterando a relação com o público atendido. Esses modelos de gestão descentralizada foram apresentados com

um entendimento de que a qualidade na educação é um objetivo mensurável que pode ser alcançado a partir de inovações incrementais na organização e gestão do trabalho na escola. Por tais razões, as mudanças vincularam o sucesso da gestão escolar ao desempenho dos alunos, aferidos sistematicamente pelo Sistema Nacional de Avaliação da Educação Básica - SAEB e, mais recentemente, os sistemas estaduais (SARESP, SIMAVE, entre outros) (OLIVEIRA et al., 2011, p.18).

De acordo com Pini e Melo (2011), as políticas desenvolvidas recentemente têm procurado revalorizar o lugar do Estado como regulador e administrador. No campo da 
educação, isso se faz evidente "com as medidas que indicam a busca pela centralização na definição de políticas educacionais por parte do Ministério da Educação" (PINI; MELO, 2011, p. 42), o que inclui as políticas de avaliação externas, que trazem consigo a defesa de um currículo nacional, constituindo uma política do conhecimento oficial (APPLE, 1994). Nessa lógica do Estado avaliador e da prestação de contas, os sistemas nacionais de avaliação da qualidade são entendidos como "mecanismos de recentralização do controle nas mãos do governo central ao mesmo tempo em que descentralizam a responsabilidade pela demonstração dos resultados educativos" (OLIVEIRA; FELDFEBER, 2011, p.30).

Entendemos que as novas formas de gestão dos sistemas educativos, desenhadas nas últimas décadas, podem ser consideradas como uma nova regulação das políticas e da ação educativa, onde as instâncias do governo central assumem funções de planejamento estratégico, estabelecem grandes objetivos e resultados esperados, "enquanto transferem a gestão dos serviços aos estados subnacionais e vão cedendo espaços ao mercado e a sociedade civil, ao mesmo tempo em que transferem responsabilidades às escolas e às famílias (Feldfeber, 2009)" (OLIVEIRA; FELDFEBER, 2011, p. 27).

Diante da impossibilidade de esgotar esse debate nos limites deste trabalho, a partir do que foi exposto até aqui, passamos, na próxima seção, à análise das políticas de avaliação que figuram, hoje, no cenário educacional brasileiro.

\section{AVALIAÇÕES EXTERNAS NO CENÁRIO BRASILEIRO: ENTRE O CONTROLE E A QUALIDADE}

Embora presente nas discussões sobre educação desde o início do século XX, é somente a partir do final da década de 1980 que a avaliação começa a assumir as dimensões que hoje possui. Associada a um viés economicista de maximização dos resultados com economia de recursos, os processos avaliativos aparecem em documentos de agências multilaterais, como o BM, como estratégias para elevação da eficiência da educação (ABOITES, 2012). É importante assinalar que, para os analistas dessa agência, com o marco que representou o corte dos gastos nas décadas de 1980 e 90, a qualidade deve ser entendida como a busca de maior eficiência na aplicação de recursos escassos (ABOITES, 2012).

Assim, para os analistas do BM a garantia da eficiência e da qualidade da educação se daria por meio da focalização do 'mundo da escola', examinando-o minuciosamente a ponto de identificar as variáveis que lá coexistem para determinar com precisão quais são os fatores que influenciam de maneira direta o desempenho escolar e quais não teriam um 
papel tão imediato nos resultados (FULLER apud ABOITES, 2012). Uma vez identificados, caberia aos gestores deixar de investir em tudo que não demonstre alguma utilidade imediata no logro dos estudantes e direcionar os recursos para os fatores que comprovadamente mais influenciam a aprendizagem e o desempenho passível de ser medido em instrumentos de avaliação.

Os impactos que essas recomendações têm sobre as políticas curriculares são previsíveis e adquirem contornos específicos em função dos contextos educacionais de cada país, que vão desde medidas de correção de fluxo e da distorção idade-série à instituição de processos de avaliação ao longo de toda a trajetória escolar, passando pela formulação de políticas curriculares, políticas de formação, bonificação pelo desempenho, entre outros. Todas essas medidas buscam dar uma resposta à questão da eficiência, que vem sendo atrelada à qualidade do processo educativo. No caso brasileiro, por exemplo, o Ministério da Educação

ampliou a abrangência do Instituto Nacional de Estudos e Pesquisas Educacionais (Inep) como órgão responsável pelos censos e pela sistematização dos indicadores educacionais gerais; criou o Sistema Nacional de Avaliação da Educação Básica (Saeb); e instituiu, ainda, os seguintes instrumentos de avaliação: Enem, Exame Nacional de Cursos (Provão), Perfil Municipal da Educação Básica e o Censo Escolar (LEHER, 2010, p. 44).

Os processos de avaliação foram adquirindo centralidade nas políticas para a educação básica, a partir 1990, com a criação do Sistema Nacional de Avaliação da Educação Básica (Saeb), que, desde 1993, é realizado em ciclos de dois anos ${ }^{4}$. A preocupação com a mensuração e a comparação dos resultados coletados nas diferentes edições da avaliação ao longo do tempo fica mais evidente a partir de 1995, quando o Inep

${ }^{4}$ O Saeb surge a partir de uma experiência pioneira desenvolvida nos anos 1980 que tinha por objetivo avaliar os efeitos do Programa de Expansão e Melhoria da Educação no Meio Rural do Nordeste (Edurural). O programa era voltado para os anos iniciais do ensino fundamental na região rural do Nordeste e contava com financiamento do Banco Mundial (HORTA NETO, 2010). 3 "Uma das grandes vantagens da TRI sobre a Teoria Clássica [dos Testes] é que ela permite a comparação entre populações, desde que submetidas a provas que tenham alguns itens comuns, ou ainda, a comparação entre indivíduos da mesma população que tenham sido submetidos a provas totalmente diferentes." Disponível em: http://portal.inep.gov.br/rss enem/-/asset publisher/oV0H/content/id/76818. Acesso em: 25 set. 2013. 
adota uma nova metodologia de construção do teste e análise de resultados, a Teoria de Resposta ao Item $(T R I)^{5}$. O sistema, inicialmente, era composto por duas avaliações complementares, a Avaliação Nacional da Educação Básica (Aneb) e a Avaliação Nacional do Rendimento Escolar (Anresc) $)^{6}$. A primeira

abrange de maneira amostral os estudantes das redes públicas e privadas do país, localizados na área rural e urbana e matriculados no 5 o e 9o anos do ensino fundamental e também no 3ㅇ ano do ensino médio. Nesses estratos, os resultados são apresentados para cada Unidade da Federação, Região e para o Brasil como um todo.

Já a Anresc

é aplicada censitariamente alunos de 50 e 9o anos do ensino fundamental público, nas redes estaduais, municipais e federais, de área rural e urbana, em escolas que tenham no mínimo 20 alunos matriculados na série avaliada. Nesse estrato, a prova recebe o nome de Prova Brasil e oferece resultados por escola, município, Unidade da Federação e país, que também são utilizados no cálculo do $l d e b^{7}$.

Ao longo desta trajetória a avaliação sofreu variadas modificações incluindo-se ou retirando da amostra a ser avaliada diferentes séries, disciplinas e tipos de unidades escolares. Contudo, pode-se dizer que o formato adotado a partir de 1995 é o que mais se assemelha ao praticado nos dias de hoje e possui diversos impactos para a educação. Talvez o mais publicizado deles seja o Ideb, um índice que agrega em seu cálculo duas variáveis: o fluxo escolar e o desempenho dos estudantes ${ }^{8}$. Segundo Nota Técnica do Inep, a potência de se agregar essas duas variáveis está no fato de que:

\footnotetext{
${ }^{5} 4$ Apesar de o Sistema de Avaliação da Educação Básica (Saeb) abranger a Aneb e a Anresc, por uma convenção social, a Aneb é referida como Saeb e a Anresc como Prova Brasil.

${ }^{6}$ Prova Brasil e Saeb. Disponível em: http://portal.inep.gov.br/web/prova-brasil-e-saeb/provabrasil-e-saeb. Acesso em: 31 ago. 20313.

${ }^{7}$ Idem à nota anterior.

${ }^{8} \mathrm{Na}$ Prova Brasil (Anresc), a média é usada para calcular os Idebs de municípios e escolas, enquanto a nota no Saeb (Aneb) subsidia o cálculo dos Idebs dos estados e do Ideb nacional. Além das notas nas avaliações, o cálculo do indicador usa as taxas de aprovação dos estudantes, informação prestada pelas redes por meio do Censo Escolar. 
Estudos e análises sobre qualidade educacional raramente combinam as informações produzidas por esses dois tipos de indicadores, ainda que a complementaridade entre elas seja evidente. Um sistema educacional que reprova sistematicamente seus estudantes, fazendo com que grande parte deles abandone a escola antes de completar a educação básica, não é desejável, mesmo que aqueles que concluem essa etapa de ensino atinjam elevadas pontuações nos exames padronizados. Por outro lado, um sistema em que todos os alunos concluem o ensino médio no período correto não é de interesse caso os alunos aprendam muito pouco na escola. Em suma, um sistema de ensino ideal seria aquele em que todas as crianças e adolescentes tivessem acesso à escola, não desperdiçassem tempo com repetências, não abandonassem a escola precocemente e, ao final de tudo, aprendessem ${ }^{9}$.

Assim, o Ideb configura-se como "ferramenta de acompanhamento das metas de qualidade da educação básica, no âmbito do Plano de Desenvolvimento da Educação (PDE), do $\mathrm{MEC}^{\prime 10}$, atendendo também àquelas orientações do $\mathrm{BM}$, que apresentamos na parte inicial dessa seção, que têm por objetivo o aumento da eficiência. Cabe dizer que as metas de qualidade trazidas pelo PDE estão também em consonância com as de um importante agente que tem conquistado espaço, que é o movimento Compromisso Todos pela Educação (TPE), o qual se apresenta

como uma iniciativa da sociedade civil e conclamando a participação de todos os setores sociais (...) [constituindo-se] de fato como um conglomerado de grupos empresariais com representantes e patrocínio de entidades como o Grupo Pão de Açúcar, Fundação Itaú-Social, Fundação Bradesco, Instituto Gerdau, Fundação Roberto Marinho, Fundação Educar- DPaschoal, Instituto Itaú Cultural, Faça Parte-Instituto Brasil Voluntário, Instituto Ayrton Senna, Cia. Suzano, Banco ABN-Real, Banco Santander, Instituto Ethos, entre outros (SAVIANI, 2009, p. 32).

O TPE, lançado em 2006, definiu metas a serem cumpridas até 7 de setembro de

${ }^{9}$ Nota Técnica - Concepção do Ideb. Disponível
em:

http://download.inep.gov.br/educacao basica/portal ideb/o que e o ideb/Nota Tecnica n1 concepcaolDEB.pdf. Acesso em: 01 set. 2013.

${ }^{10}$ As avaliações e o Ideb. Disponível em: http://portal.inep.gov.br/web/prova-brasil-e-saeb/asavaliacoes-e-o-ideb Acesso em: 01 set. 2013. 
2022, que nada mais são que

desdobramentos da Conferência Mundial de Educação para Todos da Unesco realizada em 1990, quando a comunidade internacional celebrou compromisso mundial para prover uma educação básica de qualidade a todas as crianças e a todos os jovens e adultos, e definiu a meta de universalizar a educação básica e reduzir massivamente o analfabetismo até 2015 (MOTTA, 2011, p. 137).

Embora a questão do enfrentamento do analfabetismo já estivesse presente na pauta de movimentos como o Fórum Nacional em Defesa da Escola Pública (MOTTA, 2011), chama- nos a atenção a forma como as políticas mais recentes se articulam para dar conta de velhos problemas. Por exemplo, juntamente com o Plano de Desenvolvimento da Educação (PDE), foi 'baixada', pelo Ministério da Educação, a Portaria Normativa n. $10^{11}$ que instituiu a "Provinha Brasil", avaliação destinada aos estudantes de 2o ano do Ensino Fundamental, que tem por objetivo, como definido em seu Artigo 20․

a) avaliar o nível de alfabetização dos educandos nos anos iniciais do ensino fundamental;

b) oferecer às redes de ensino um resultado da qualidade do ensino, prevenindo o diagnóstico tardio das dificuldades de aprendizagem; $e$

c) concorrer para a melhoria da qualidade de ensino e redução das desigualdades, em consonância com as metas e políticas estabelecidas pelas diretrizes da educação nacional.

Fica evidente, então, que dá-se à avaliação o papel de fornecer informações sobre a qualidade da educação e apontar caminhos para a melhoria dessa qualidade (SAVIANI, 2009). Mais recentemente foi instituído o Pacto Nacional pela Alfabetização na Idade Certa ${ }^{12}$ (PNAIC) que compreende quatro eixos de ações: i) formação continuada de professores alfabetizadores; ii) materiais didáticos, literatura e tecnologias educacionais; iii) avaliação e; iv) gestão, controle e mobilização social. Com o Pacto, além da Provinha Brasil, acrescenta-se

$10^{11}$ Portaria Normativa no 10, de 24 de abril de 2007. Disponível em: http://download.inep.gov.br/educacao_basica/provinha_brasil/legislacao/2007/provinha_brasi I_portaria_normativa_n10_24_abr il_2007.pdf. Acesso em: 25 set. 2013.

${ }^{12}$ Instituído pela Portaria MEC n. 867, de 4 de julho de 2012. 
também ao ciclo de alfabetização a Avaliação Nacional de Alfabetização (ANA).

A ANA, juntamente com a Aneb e a Anresc, passa a integrar o 'novo' Sistema de Avaliação da Educação Básica ${ }^{13}$, que acompanha os indivíduos ao longo de toda a sua trajetória escolar. Apesar de muito sutil, é possível perceber uma mudança na orientação dos documentos que estruturam a Provinha Brasil e o Pacto Nacional pela Alfabetização na Idade Certa. Ainda que ambos compartilhem a noção da garantia da qualidade da educação, o primeiro traz a avaliação como um instrumento capaz de prover às redes de ensino um conjunto de informações que as auxiliem no diagnóstico da alfabetização, prevenindo que este seja realizado tardiamente e vincula o seu atingimento à redução das desigualdades sociais. Já no segundo, a avaliação divide esse lugar 'privilegiado' com os materiais didáticos, a formação docente e a gestão, o que nos faz suspeitar que não se constituirá apenas como um parâmetro de monitoramento da qualidade, pois, ao articular-se com a formação e a gestão pode dar indícios de quem são os profissionais que estão desempenhando 'bem' o seu trabalho e as instituições que empregam de maneira eficiente os recursos.

É importante reconhecer que essa vinculação de índices de desempenho com políticas de gestão, formação e de produção de materiais didáticos não representam uma novidade, afinal temos o exemplo do Ideb. A surpresa talvez resida no fato de que, dessa vez, tais dimensões venham em um único pacote que é o Pacto Nacional pela Alfabetização na Idade Certa. Nesse contexto, chama a atenção que determinados grupos com forte influência sobre a produção dessas políticas, tenham como prolongamentos tanto grandes corporações no setor editorial, que produzem apostilas padronizadas, como ONGs, que atuam em capacitação docente e gerencial, expropriando os professores de seu trabalho intelectual (EVANGELISTA; LEHER, 2012). Como bem nos alerta Motta (2011, p.124),

temos clareza das concepções de educação e de sociedade que esse grupo representa e expressa: situadas nos limites das necessidades do mercado e do grande capital, com abordagens de políticas públicas funcionalistas e tecnocráticas que, passando ao largo das raízes da "questão social" e suas implicações na sociedade e na educação brasileiras, focam na "gestão de qualidade" a superação dos "males" da educação pública.

Não é possível deixar de reconhecer os efeitos que tais políticas de avaliação

${ }^{13}$ Alteração dada pela Portaria Inep/Mec no 304, de 21 de junho de 2013. 
têm sobre o sistema educacional brasileiro e o cotidiano das escolas. Basta conversar com docentes das redes públicas da Educação Básica e atentar para os movimentos grevistas atuais para perceber que tais instrumentos de avaliação têm servido, em muitos casos, "como controle do trabalho docente por meio de premiação aos professores cujos alunos apresentam desempenho satisfatório e o contrário, maior pressão e cobrança daqueles cujos alunos não apresentam bom desempenho" (OLIVEIRA; FELDFEBER, 2011, p.29).

Também não é possível deixar de considerar que este cenário corre sérios riscos tanto de não contribuir para a qualidade da educação tão propalada quanto de propiciar, em última instância, o acirramento das desigualdades sociais. Sem nos mantermos ingênuos em relação a esses e muitos outros aspectos e considerando a relevância teórica, epistemológica e política das perspectivas até aqui comentadas, temos investido em análises distintas, em diálogo com autores do campo do Currículo. Nesse sentido, entendemos as políticas de avaliação como políticas públicas, mas também como políticas curriculares produzidas discursivamente que, ao mesmo tempo em que contribuem para a configuração de uma política do conhecimento oficial (APPLE, 1994), influenciam movimentos curriculares que nos interessam estudar, interpretando tais movimentos como parte de uma dimensão produtiva do trabalho docente. É sobre tais aspectos que nos detemos na próxima seção.

\section{POLÍTICAS DE AVALIAÇÃO COMO POLÍTICAS CURRICULARES: APOSTANDO NA QUALIDADE}

Como que em um estado de impasse diante da reflexão sobre o cenário educacional contemporâneo e as políticas oficiais que buscam organizá-lo, ao longo dos últimos anos temos procurado a interlocução com autores do campo do Currículo, considerando a centralidade do currículo nas reformas atuais da educação. Esses autores vêm problematizando as políticas curriculares como políticas públicas, na intenção de entendê-las como produções culturais e discursivas, permeadas por relações de poder, que envolvem diversos atores em múltiplos contextos.

Temos interpretado, em diálogo com Dias (2009), o currículo e as políticas curriculares como políticas culturais públicas, definidas em arenas de negociação de sentidos relacionadas às políticas sociais mais amplas do país e marcadas por uma dinâmica de complexidades sempre contingente e provisória. Ao analisar a produção nacional e internacional sobre políticas públicas e os contextos das reformas educacionais, privilegiando autores brasileiros das ciências sociais e da educação, Dias (2009) aponta para o relevo dado ao papel dos organismos internacionais, em diversos estudos que exploram 
suas ações nos mais variados setores e com distintas abrangências.

Segundo Dias (2009, p.28) nessas análises, em que se dá um maior destaque para o âmbito macro e para uma visão verticalizada do poder, "é enfatizado o caráter de coerção desses organismos como instrumentos diretos dos Estados hegemônicos e dos interesses econômicos globais (Melo, 2004, p. 170-1)". Em diálogo com autores do campo do Currículo, de forma distinta desses estudos, pensamos as relações de mútua influência entre contextos globais e locais. Deste modo, sem desconsiderar o cenário mais amplo de influências de organismos multilateriais e do empresariado, procuramos dar relevo aos atores sociais que disputam discursivamente pela significação das políticas em cenários mais localizados, tais como instituições educacionais e espaços de debate acadêmico.

Baseando-nos na abordagem do Ciclo de Políticas de Stephen Ball, operamos com uma ideia de políticas curriculares para além de um movimento verticalizado, em contraposição a perspectivas que entendem tais políticas ou como um movimento de 'cima' para 'baixo', marcado pelo poder central e pelos governos, ou como um movimento de 'baixo' para 'cima', tendo na prática seu campo de produção (PAIVA et al., 2006). Em nossos trabalhos, temos investido em análises que buscam operar com uma concepção de poder menos linear, vertical e hierárquica, nos distanciando de perspectivas que vem caracterizando tanto os trabalhos no campo do Currículo quanto os trabalhos em Políticas Públicas (DIAS, 2009), no Brasil, negligenciando, muitas vezes, "os espaços de resistência [e subversão] abertos por ações não previstas, dificultando que sejam vislumbradas alternativas a não ser as relacionadas a modificações na estrutura econômica e política" (MACEDO, 2006, p. 103).

Assim, compreendemos os processos de produção de políticas curriculares, dentre elas as políticas de avaliação, a partir da perspectiva de Stephen Ball, que investiga as políticas educacionais considerando as articulações e reinterpretações em múltiplos contextos, onde ocorrem conflitos e disputas pela negociação de sentidos e de significados. O autor busca repensar e desconstruir uma compreensão hierárquica acerca da relação entre os contextos, os quais se articulam de forma permanente, e também opera com uma concepção mais oblíqua de poder, se distanciando de um modelo de análise centrado no controle do Estado, ainda que reconheça que tanto o Estado quanto outras instâncias locais, como as escolas, têm distintas posições de legitimidade e poder ao longo do processo de produção das políticas.

Segundo Ball e Bowe (BOWE et al., 1992), no contexto de influência, onde 
acontecem disputas em torno da significação acerca das finalidades sociais da educação, atuam redes sociais dentro dos partidos políticos, do governo, do processo legislativo, das agências multilaterais e das comunidades epistêmicas. No contexto de definição dos textos políticos atuam as instâncias do governo, em estreita associação com o contexto anterior, produzindo e disseminando os textos e discursos das definições políticas. No contexto da prática, onde atuam grupos sociais em instituições como as escolas e as universidades, as políticas são continuamente produzidas e os discursos das propostas curriculares oficiais são recontextualizados, hibridizados e ressignificados, sendo recriados e reinterpretados pelos sujeitos aí envolvidos ${ }^{14}$.

Entendemos que em todas as arenas que configuram os três contextos descritos acima, ocorrem permanentes conflitos e disputas pela negociação de sentidos e significados em torno dos propósitos sociais da educação e das definições das políticas em processo de construção. Desse modo, as políticas curriculares devem ser pensadas como a construção de um ciclo contínuo marcado por uma heterogeneidade de discursos, que sofrem constantes processos de recontextualização e de hibridismo (LOPES, 2005), e por uma diversidade de sujeitos e de grupos sociais que dele participam.

Gabriel et al. (2008, p.261) apontam que a tensão entre homogeneidade/heterogeneidade pode ser percebida em uma tentativa de controle que, permanentemente, escapa aos sistemas globais. Nesse movimento, os sujeitos sociais dos sistemas locais "negociam os vários sentidos, híbridos e ambivalentes, em disputa pela hegemonia $^{15}$, ainda que contingente, dos discursos sobre [as questões educacionais]". No processo de produção das políticas de currículo, esses discursos acabam por circular em diversas instâncias, influenciando a elaboração e a hibridização dos discursos veiculados nos sistemas globais. Ao nos apoiarmos em Gabriel et al. (2008), nos distanciamos de uma análise que focaliza a denúncia e buscamos trabalhar em uma pauta que privilegia a linguagem das possibilidades. Ao operar com as noções de circularidade e de subversão, associando-as ao conceito de hibridismo, apostamos que essas categorias de análise podem trazer novos

${ }^{14}$ Para além destes três principais contextos, Ball (1994 apud MAINARDES, 2006) propõe em trabalho posterior dois outros contextos que se articulariam com os outros na abordagem do ciclo de políticas - o contexto dos resultados (efeitos) e o contexto da estratégia política. O contexto dos resultados ou dos efeitos consideraria os impactos de uma determinada política e sua articulação com as desigualdades existentes. O contexto da estratégia política, por sua vez, envolveria a "identificação de um conjunto de atividades sociais e políticas que seriam necessárias para lidar com as desigualdades criadas ou reproduzidas pela política investigada" (MAINARDES, 2006).

${ }^{15}$ Importante ressaltar que as autoras operam com a concepção de hegemonia de Ernesto Laclau, vinculada às Teorias Sociais do Discurso, em perspectiva pós-marxista. 
olhares para uma reflexão acerca dos processos de produção das políticas de currículo ${ }^{16}$.

Uma análise da configuração atual das avaliações externas nos dá alguns indícios de da circularidade na elaboração das políticas de avaliação. Um exemplo é a realização de chamadas públicas para a convocação de docentes interessados em elaborar e revisar itens para a composição de instrumentos de avaliação. Como publicizado na página do Inep, o órgão vem realizando essas chamadas públicas de docentes, direcionadas a pessoas físicas ou instituições de ensino, desde 2010, contemplando uma ampla gama das avaliações e exames conduzidos pelo instituto ${ }^{17}$. Tais chamadas públicas

fazem parte de um processo mais amplo de estruturação para que - INEP assuma diretamente a responsabilidade pela montagem dos seus instrumentos de avaliação, constituindo, para tal, um sistema de elaboração e revisão de itens, o BNI (Banco Nacional de Itens). Tem-se como intuito, também, aumentar a participação da comunidade acadêmica de todo o Brasil nos processos de avaliação educacional desenvolvidos por este instituto ${ }^{18}$.

Sem sermos ingênuos e acharmos que a participação desses docentes permite toda e qualquer subversão, entendemos que sua circulação nessa esfera da produção possibilita que determinados discursos produzidos no contexto da prática informem, também, a produção de diversos instrumentos que compõem as políticas de avaliação. Desta forma, nos distanciamos de uma perspectiva de que tais políticas são produzidas unicamente pelo Estado e nos aproximamos de uma perspectiva de que são produções culturais que envolvem processos de recontextualização de discursos que circulam em distintos contextos e por diversos sujeitos e grupos, que se hibridizam e se ressignificam.

É a partir dessa circulação que se torna possível identificar elementos que estão presentes e foram construídos no contexto da prática nos instrumentos utilizados para avaliar os estudantes em escala nacional. Reconhecemos o papel e a importância que possuem os documentos que instituem essas políticas e os efeitos que deles decorrem, mas não podemos

${ }^{16}$ Como foge ao nosso escopo a apresentação de produções que operam com essas categorias, sugerimos a leitura de Terreri (2008) e Santos (2010).

17 A leitura da página do Inep nos permitiu identificar chamadas públicas de docentes e instituições para a elaboração e revisão de itens para a Provinha Brasil, Prova Brasil e Exame Nacional do Ensino Médio para citar apenas as avaliações e exames da educação básica.

18 Participação no processo de elaboração/revisão de itens. Disponível em: http://bni.inep.gov.br/inscricao/ Acesso em: 01 set.

2013. 
deixar de dar luz ao caráter produtivo que a participação de docentes, que atuam nos mais diversos contextos educativos, traz ao processo de produção e implementação de tais políticas.

Operar com a abordagem do Ciclo de Políticas e com uma noção produtiva de poder também nos permite focalizar o que tem sido produzido nos currículos da Educação Básica, no contexto da prática, em diálogo com as políticas de avaliação atuais. Se entendemos que o ciclo de políticas se dá de forma contínua e simultânea, nos afastamos de um olhar dicotômico que entende que as políticas são produzidas em instâncias externas à escola e aí implementadas. Na perspectiva em que nos situamos, interpretamos que os instrumentos de avaliação em larga escala utilizados atualmente influenciam movimentos e escolhas curriculares no contexto da prática. No entanto, os sujeitos que aí circulam abrem espaços e tempos para leituras heterogêneas e para subversão, contribuindo para a continuidade da produção dessas políticas.

Esse olhar permite que focalizemos a contínua circulação de discursos e sentidos entre os contextos, os aspectos produtivos do poder, bem como o protagonismo desses atores na elaboração das políticas públicas em que, mesmo com os constrangimentos próprios das relações de poder nas quais se inserem ao participar de tais processos, possibilita o fortalecimento da luta em torno da autonomia docente e da qualidade da educação. Assim, os docentes, ainda que impactados por tais políticas, que trazem em seu bojo um forte viés de controle e de obtenção de resultados previamente projetados, estão continuamente produzindo currículos nas instituições escolares.

Reconhecemos que as políticas de avaliação podem contribuir para um estreitamento da autonomia docente, mas ao chegarem às instituições escolares precisam conviver e disputar espaço com uma série de tradições historicamente construídas naquele espaço (FERREIRA, 2005; TERRERI, 2008; SANTOS, 2010). Acreditamos que esse diálogo entre políticas e tradições que convivem no espaço escolar acabam por produzir deslizamentos que produzem novos sentidos e possibilitam ações para além das previstas inicialmente, colaborando também para um incremento da qualidade da educação.

\section{BUSCANDO CONCLUIR}

Neste texto, buscamos traçar um panorama das políticas de avaliação atuais que figuram no cenário educacional brasileiro, ressaltando alguns elementos históricos que 
contribuíram para a consolidação das mesmas. Entendendo a atividade acadêmica como atividade política e discursiva, de luta por significação, apresentamos a perspectiva com a qual vimos dialogando, apostando em sua fertilidade para compreender as políticas de avaliação como políticas curriculares produzidas em meio a disputas e lutas discursivas por significação em torno dos propósitos sociais da educação.

Defendemos que essa perspectiva nos permite pensar a qualidade para além de uma mera garantia da eficiência ou, em outras palavras, de se fazer mais com menos. Dessa forma, devolvemos aos docentes o papel da militância e recuperamos o sentido que lutas históricas de educadores e educadores têm empreendido, possibilitando pensar a escola também como um local de produção de políticas curriculares que buscam possibilitar a emancipação via processo educativo.

Focalizando os deslizamentos de sentidos, as ações diversas e as subversões que a multiplicidade de sentidos inerentes às políticas curriculares possibilitam no contexto da prática, não deixamos de considerar "a permanência de tensões e a produção de novas contradições nos processos de subversão" (GABRIEL et al,. 2008, p. 255). A opção por essa abordagem não representa uma tentativa de esvaziamento das relações de poder. De outro modo, "aponta para [outras] formas possíveis de [pensar] as relações de poder e as escalas de análise para além das visões dicotômicas e verticalmente hierarquizadas que ainda persistem nos estudos sobre currículo" (GABRIEL et al., 2008, p. 256), especialmente, nos que focalizam as políticas de currículo. Em diálogo e subvertendo as políticas de avaliação, outros currículos são continuamente produzidos nas instituições escolares. Deste modo, ainda que seja inegável a redução da autonomia dos professores, apostamos na dimensão produtiva desta profissão, como condição de luta em defesa da qualidade da escola pública.

\section{REFERÊNCIAS}

ABOITES, H. La medida de uma nación: los primeiros años de la evaluación em Mexico historia de poder Y resistência (1982-2012). Mexico: D.F. Casa Abierta ao Tempo; Buenos Aires: CLACSO, 2012.

APPLE, M. W. A política do conhecimento oficial: faz sentido a ideia de um currículo nacional? In: MOREIRA, A. F. B.; SILVA, T. T. Currículo, cultura $e$ sociedade. São Paulo: Cortez, p. 59-92, 1994.

BOWE, R.; BALL, S. J.; GOLD, A. The policy processes and the processes of policy. In: BOWE, R.; BALL, S. J.; GOLD, A. (orgs.). Reforming education and changing schools: case studies in policy sociology. Londres/Nova lorque: Routledge, p. 6-23, 1992. 
DIAS, R. E. Ciclo de políticas curriculares na formação de professores no Brasil (1996-2006). Tese de Doutorado. Rio de Janeiro: Proped/UERJ, 2009.

EVANGELISTA, O.; LEHER, R. Todos pela Educação e o episódio Costin no MEC: a pedagogia do capital na política educacional brasileira. Trabalho Necessário. n. 15-2012.

FERREIRA, M. S. A história da disciplina escolar Ciências no Colégio Pedro II. Tese de Doutorado. Rio de Janeiro: FE/UFRJ, 2005.

GABRIEL, C. T. A.; FERREIRA M. S.; MONTEIRO, A. M. Democratização da universidade pública no Brasil: circularidades e subversões nas políticas de currículo. In: LOPES, A. C.; LOPES, A.; LEITE, C.; MACEDO, E.; TURA, M. de L. (Org.). Políticas Educativas e dinâmicas curriculares no Brasil e em Portugal. Rio de Janeiro: DP et Alii, v. 1, p. 251-266, 2008.

HORTA NETO, J. L. Avaliação externa de escolas e sistemas: questões presentes no debate sobre o tema. Revista Brasileira de Estudos Pedagógicos. Brasília, v. 91, n. 227, p.84-104, jan./abr. 2010.

LEHER, R.; SADER E. Público, estatal e privado na reforma universitária. Texto elaborado para o INEP, 2004. (Mimeo).

LEHER, R. A problemática da universidade 25 anos após a 'crise da dívida'. Universidade e Sociedade. Distrito Federal, ano XVI, n. 39, p. 9-15, fev. 2007.

LEHER, R. 25 Anos de Educação Pública: notas para um balanço do período. In: Trabalho, Educação e Saúde - 25 anos de formação politécnica no SUS. Rio de Janeiro: Escola Politécnica de Saúde Joaquim Venâncio, 2010.

LOPES, A. C. Política de currículo: recontextualização e hibridismo. Currículo sem Fronteiras, v.5, n.2, p. 50-64, 2005.

MACEDO, E. Currículo: política cultura e poder. Currículo sem Fronteiras, v. 6, n. 2, p. 98-113, 2006.

MAINARDES, J. Abordagem do Ciclo de Políticas: Uma Contribuição para a Análise de Políticas Educacionais. Educação e Sociedade. v. 27, n. 94, p. 47-69, jan/abr. 2006.

MOTTA, V. C. Educação como caminho, mas qual?: Todos pela Educação ou em Defesa da Escola Pública? In: BERTUSSI, G.T.; OURIQUES, N.D. (coord.) Anuário educativo brasileiro: visão retrospectiva. São Paulo: Cortez, 2011.

OLIVEIRA, D. A.; FELDFEBER, M. Novas e velhas formas de regulação dos sistemas educativos no Brasil e da Argentina. In: OLIVEIRA, D. A.; PINI, M. E.; FELDFEBER, M. (Orgs.). Políticas educacionais e trabalho docente: perspectiva comparada. Belo Horizonte: Fino Traço, p. 25-40, 2011.

OLIVEIRA, D. A.; PINI, M. E.; FELDFEBER, M. Políticas educacionais e formas de regulação: um estudo comparado entre Brasil e Argentina. In: OLIVEIRA, D. A.; PINI, M. E.; FELDFEBER, M. (Orgs.). Políticas educacionais e trabalho docente: perspectiva comparada. Belo Horizonte: Fino Traço, p. 11-24, 2011.

PAIVA, E. V.; FRANGELLA, R. de C. P.; DIAS, R. E. Políticas curriculares no foco das investigações. 
In: LOPES, A. C. ; MACEDO, E. (orgs.). Políticas de currículo em múltiplos contextos. São Paulo: Cortez. p. 241-269, 2006.

PINI, M. E.; MELO, S. D. G. Argentina e Brasil: mudanças e contradições nas políticas educacionais. In: OLIVEIRA, D. A.; PINI, M. E.; FELDFEBER, M. (Orgs.). Políticas educacionais e trabalho docente: perspectiva comparada. Belo Horizonte: Fino Traço, p. 41-62, 2011.

SANTOS, A. V. F. Investigando a disciplina escolar Educação Ambiental em Armação dos Búzios, RJ: entre histórias e políticas de currículo. Dissertação de Mestrado. Rio de Janeiro: PPGE/UFRJ, 2010.

SAVIANI, D. PDE - Plano de Desenvolvimento da Educação: Análise crítica da política do MEC. Campinas, SP: Autores Associados, 2009.

SHIROMA, E. O.; EVANGELISTA, O. Professor: protagonista e obstáculo da reforma. Revista Educação e Pesquisa. São Paulo, v.33, n.3, p. 531-541, set/dez. 2007.

TERRERI, L. Políticas curriculares para a formação de professores em Ciências Biológicas: investigando sentidos de prática. Dissertação de Mestrado. Rio de Janeiro: PPGE/UFRJ, 2008. TODOS PELA EDUCAÇÃO. As 5 metas. Disponível em: http://www.todospelaeducacao.org.br/institucional/as-5-metas/. Acesso em: 31 ago. 2013. 